\title{
1 Passive sampling of environmental DNA in 2 aquatic environments using 3D-printed 3 hydroxyapatite samplers
}

3 INRAE, UR-Riverly, Centre de Lyon-Villeurbanne, 5 rue de la Doua CS70077, 69626 VILLEURBANNE Cedex, France

${ }^{4}$ 3d.FAB, Univ Lyon, Université Lyon1, CNRS, INSA, CPE $\square$ Lyon, ICBMS, UMR 5246, 43, Bd

${ }^{5}$ INRAE, USMB, UMR CARRTEL, 75bis av. de Corzent, 742000 Thonon les Bains, France

${ }^{6}$ Univ Lyon, INSA Lyon, UCBL, CNRS, MATEIS UMR 5510, 69621 Villeurbanne, France

Corresponding authors :

Héloïse Verdier, Univ Lyon, Université Claude Bernard Lyon 1, CNRS, ENTPE, UMR 5023 LEHNA, Villeurbanne, France, heloise.verdier@univ-lyon1.fr

Tristan Lefébure, Univ Lyon, Université Claude Bernard Lyon 1, CNRS, ENTPE, UMR 5023 LEHNA, Villeurbanne, France, tristan.lefebure@univ-lyon1.fr 


\section{Abstract}

50 Key-words : DNA Binding, Environmental DNA, Hydroxyapatite, Passive sampling, 3D-

51 printing

1. The study of environmental DNA released by aquatic organisms in their habitat offers a fast, non-invasive and sensitive approach to monitor their presence. Common eDNA sampling methods such as filtration and precipitation are time consuming, require human intervention and are not applicable to a wide range of habitats such as turbid waters and poorly-accessible environments. To circumvent these limitations, we propose to use the binding properties of minerals to create a passive eDNA sampler.

2. We have designed 3D-printed samplers made of hydroxyapatite (HAp samplers), a mineral known for its high binding affinity with DNA. The shape and the geometry of the samplers have been designed to facilitate their handling in laboratory and field. Here we describe and test the ability of HAp samplers to recover artificial DNA and eDNA.

3. We show that HAp samplers efficiently recover DNA and are effective even on small amounts of eDNA (<1 ng). However, we also observed large variations in the amount of DNA recovered even under controlled conditions.

4. By better understanding the physico-chemical interactions between DNA and the HAp sampler surface, one could improve the repeatability of the sampling process and provide an easy-to-use eDNA sampling tool for aquatic environments. 


\section{1 | INTRODUCTION}

56 At a time of unprecedented threats on freshwater biodiversity, it is crucial to develop rapid,

57 accurate and minimally invasive tools to monitor aquatic ecosystems. About a decade ago,

58 methods based on the sampling of environmental DNA (eDNA) were proposed as a

59 revolutionary way to survey aquatic macro-organisms (Deiner et al., 2017). Macro-organisms

60 release DNA in their environment through different processes (e.g. faeces, excretion,

61 shedding cells, gametes) and this eDNA can take different forms (tissues, cells, organites,

62 nucleo-proteic complexes, ...). The direct sampling of eDNA coupled with molecular analysis

63 methods such as NGS (Shokralla et al., 2012) or quantitative polymerase chain reaction

64 (qPCR) (Langlois et al., 2020) allow the detection and identification of aquatic species while

65 overcoming organism capture. Although eDNA offers many promising applications, several

66 methodological challenges remain.

67

68 One of the most challenging aspects of eDNA-based approaches is the sampling method.

69 eDNA is present in very small quantities and is heterogeneously distributed in aquatic

70 environments (Goldberg et al., 2016). To maximise its recovery, sampling methods must be

71 able to concentrate eDNA (Hinlo et al., 2017). Active filtration of a large volume of water is the

72 most commonly-used method to recover eDNA in aquatic systems. However, filtration has

73 significant methodological limitations. Firstly, it is a long and tedious process requiring human

74 intervention, sometimes difficult to carry out in poorly-accessible habitats. Secondly, the

75 clogging of the filters is a recurrent problem which reduces the volume of water that can be

76 sampled (Williams, Huyvaert and Piaggio, 2017). 
78 To limit clogging, filtration membranes with large porosity (greater than $0.45 \mu \mathrm{m}$ ) are often

79 used. However, eDNA particles can be present in various forms (intra or extracellular), states

80 (free or complexed with other particles) and sizes (from $>180$ to $<0.2 \mu \mathrm{m}$ but most abundant

81 between 0.2 and $10 \mu \mathrm{m}$ ) (Turner et al., 2014; Moushomi et al., 2019 ; Wilcox et al., 2015). As

82 filtration is based on particle size sorting, the use of membranes with large porosity will

83 overlook smaller DNA particles, even though they may be an important source of eDNA

84 (Moushomi et al., 2019). Finally, given the complex dynamic of eDNA in aquatic environments

85 (i.e. pulsed emission, transport, retention, degradation), one filtration sample will provide an

86 instantaneous snapshot which is likely to be poorly integrative of the overall eDNA signals

87 (Pilliod et al., 2013; Spear et al., 2015).

88

89 Passive eDNA sampling using natural substrates is a promising solution to overcome filtration

90 challenges. Organisms such as marine sponges (Mariani et al., 2019), molluscs (Der

91 Sarkissian et al., 2020) and biofilms (Rivera et al., 2021) can trap and accumulate eDNA

92 particles in water. Minerals can also accumulate and protect DNA from enzymatic degradation

93 (Alvarez et al., 1998; Levy-Booth et al., 2007). Indeed, a sample of sediment can contain

94 more eDNA than a water sample (Turner, Uy and Everhart, 2015). Recently, Kirtane and

95 colleagues (Kirtane, Atkinson and Sassoubre, 2020) have shown that montmorillonite and

96 coal-based mineral powders can be used as passive eDNA samplers in aquatic

97 environments. Thanks to good DNA capture and preservation rates (up to $200 \mu \mathrm{g}$ genomic

98 DNA / g) (Gardner and Gunsch, 2017), sediments and commercial mineral powders may very

99 well be more integrative eDNA substrates than filtration methods. Yet, these substrates are

100 difficult to handle and deploy in the environment, particularly in aquatic systems. 
bioRxiv preprint doi: https://doi.org/10.1101/2021.05.12.443744; this version posted May 14, 2021. The copyright holder for this preprint (which was not certified by peer review) is the author/funder, who has granted bioRxiv a license to display the preprint in perpetuity. It is made available under aCC-BY-NC-ND 4.0 International license.

102 In this study, as an alternative to filtration, we developed proof of concept 3D-printed passive 103 eDNA samplers. 3D printing allows control of the shape and composition of an object. The 104 shape of the samplers were designed with optimised surface/volume -ratio and a shape 105 easing handling in the field and in the lab. The samplers were made of pure hydroxyapatite 106 (HAp), a calcium phosphate mineral naturally present in bones and known for its high binding 107 affinity toward DNA (Okazaki et al., 2001; Brundin et al., 2013). Here we describe the 108 development of hydroxyapatite samplers (HAp samplers) and test their ability to sample 109 eDNA in fresh waters. Two prototypes of samplers will be presented: a first test-version, with 110 which the concept and material will be tested, and a second version which shape and design

111 have been optimised for eDNA sampling. Using controlled laboratory experiments, our 112 objectives are to (i) quantify the HAp samplers DNA binding and release capacity, (ii) assess 113 the range of DNA fragment size sampled, (iii) quantify the repeatability of DNA sampling 114 across several cycles of use of the HAp samplers, and (iv) evaluate the samplers capacity to 115 sample eDNA released by organisms in microcosm.

\section{2 | MATERIALS AND METHODS}

1182.1 | 3D-printed HAp samplers design

119 2.1.1 | Raw material and printing setup

120 A photopolymerizable organic resin (3D Mix, 3DCeram Company, HAP, Bonnac-la-Côte,

121 France) containing 40-60 \% (w/v) of hydroxyapatite powder $\left(\mathrm{Ca}_{10}\left(\mathrm{PO}_{4}\right)_{6}(\mathrm{OH})_{2}\right.$, stoichiometric 122 hydroxyapatite), a synthetic calcium phosphate with $\mathrm{Ca} / \mathrm{P}$ atomic ratio of 1.67 , was the raw 123 material used to fabricate the samplers. The samplers were built from this hydroxyapatite- 
124 enriched resin using a 3D stereolithographic printer (CERAMAKER C900, 3DCeram

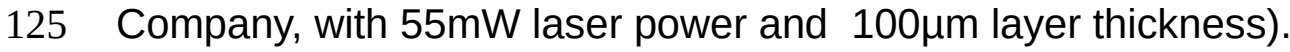

126 Two types of prototypes of HAp samplers were produced. The first prototype (P1) is a test

127 version corresponding to 10 pieces cut out of a 3D-printed mesh (Fig. 1a). P1 prototypes

128 have an exposed surface of $240 \mathrm{~mm}^{2}$ and a macroporosity of $500 \mu \mathrm{m}$ in diameter. A second

129 more elaborate prototype (P2) was then produced with optimized geometry and porosity, and

130 printed in 25 copies (Fig. 1b). P2 has a total surface of $480 \mathrm{~mm}^{2}$ and a macroporosity of 400

$131 \mu \mathrm{m}$ in diameter.

132

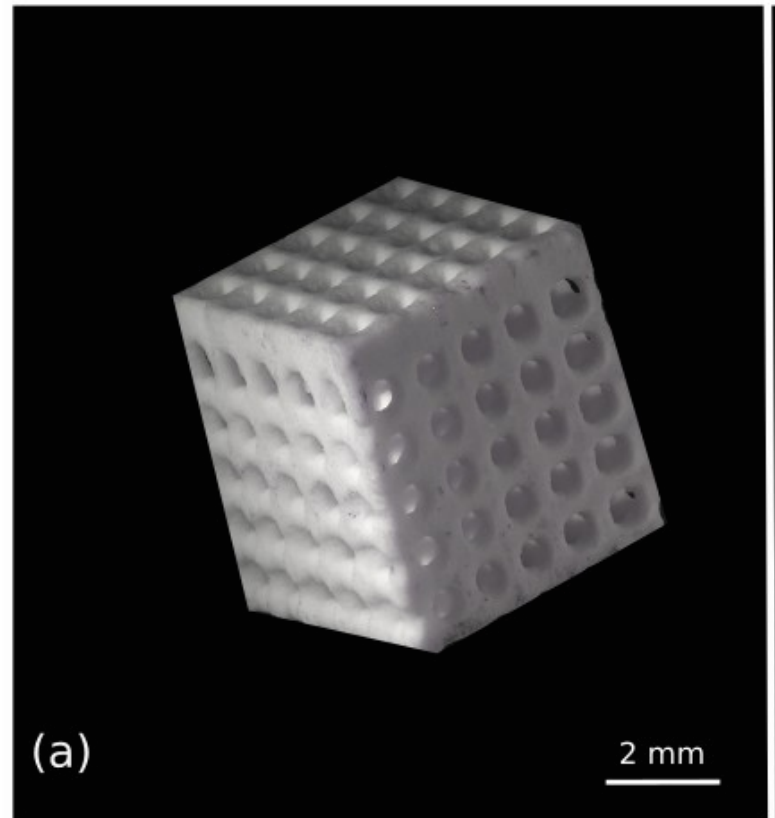

133 FIGURE 1: Images of 3D-printed hydroxyapatite samplers prototype P1 (a) and P2 (b)

134 obtained with a confocal microscope (objective x0.5, LEICA Z16 APO, camera LEICA 135 DMC5400). 
138 Once printed, cleaned with a specific solvent (Ceracleaner, 3DCeram Company, Bonnac-la-

139 Côte, France) and dried, the HAp samplers underwent debinding and sintering steps.

140 Debinding aims at removing all organic components (in particular the organic resin) and was

141 conducted in a conventional oven following the thermal cycle described in Table 1.

142 TABLE 1 : Process parameters for debinding HAp samplers

\begin{tabular}{|l|l|l|l|}
\hline Step & Temperature $\left({ }^{\circ} \mathrm{C}\right)$ & $\begin{array}{l}\text { Heating rate } \\
\left({ }^{\circ} \mathrm{C} / \mathrm{min}\right)\end{array}$ & Dwell (min) \\
\hline 1 & $20-200$ & 0,2 & 120 \\
\hline 2 & $200-300$ & 0,1 & 120 \\
\hline 3 & $300-380$ & 0,1 & 120 \\
\hline 4 & $380-550$ & 0,1 & 120 \\
\hline 5 & $550-950$ & 1 & 0 \\
\hline 6 & $950-20$ & 2 & - \\
\hline
\end{tabular}

145 Sintering aims at consolidating the samplers by densifying them (creation of necks and

146 reduction of the porosity between the individual ceramic particles) (Rahaman, 2017), and is

147 achieved by a thermal treatment at higher temperature $\left(1^{\circ} \mathrm{C} / \mathrm{min}\right.$ up to $1150^{\circ} \mathrm{C}, 60 \mathrm{~min}$. at

$1481150^{\circ} \mathrm{C}$, followed by a second step at $3^{\circ} \mathrm{C} / \mathrm{min}$ up to $1250^{\circ} \mathrm{C}, 60 \mathrm{~min}$ at $1250^{\circ} \mathrm{C}$, finally cooling

149 to room temperature at $3^{\circ} \mathrm{C} / \mathrm{min}$ ). After sintering, no additional processing (i.e. finishing or

150 polishing) was performed. The presence of pure HAp was confirmed by X-ray diffraction

151 (XRD) performed on as-sintered samples.

152

1532.2 | Expected DNA recovery from HAp samplers 
154 We used the term "DNA recovery" to define the quantity of DNA that binds and is released

155 from the HAp samplers. We estimated the theoretical maximum DNA recovery (DNA $\left.A_{\max }\right)$

156 based on the hypothesis that a single layer of DNA molecules would bind on the HAp surface

157 of the samplers. According to equation 1, the number of DNA molecules that can bind to the 158 surface is obtained by dividing the exposed surface $(\mathrm{Se})$ of a sampler $\left(\mathrm{P} 1=240 \mathrm{~mm}^{2}, \mathrm{P} 2=\right.$ $\left.159480 \mathrm{~mm}^{2}\right)$ by the surface of a DNA base pair $\left(\mathrm{Sd}=6.46 \mathrm{E}-10 \mathrm{~mm}^{2}\right)$. The surface of a DNA 160 base pair was calculated according to Mandelkern et al (1981) (diameter $=2 \mathrm{~nm}$, length $=3.4$ $161 \mathrm{~nm})$. The number of DNA molecules per sampler is then divided by Avogadro's constant (NA = $1626.02214076 \times 1023 \mathrm{~mol}-1)$ to give the number of DNA moles per sampler. The number of 163 moles of DNA is then divided by the molar mass of a DNA base pair ( $\mathrm{W}=650$ daltons) to 164 obtain the total mass of DNA that can bind to a sampler. Being smaller, P1 has a maximum 165 theoretical recovery capacity of $400 \mathrm{ng}$ of DNA per sampler, while P2 has a capacity of 800 $166 \mathrm{ng}$.

$$
D N A \max =(S t / S d) / N A \times W
$$

\section{Equation 1}

168

\section{3 | Protocol of DNA binding and release}

170 The HAp sampler DNA binding and release protocol is composed of 5 steps. First, HAp

171 samplers are decontaminated before each experiment by a thermal treatment in air at $550^{\circ} \mathrm{C}$

172 for 3 hours (Thermolyne model 30400 furnace), a procedure typically used to decontaminate

173 glassware. Second, DNA is bound to the HAp samplers by immersing them in an aqueous

174 solution (varying composition upon the present study) containing DNA. Third, samplers are

175 transferred to Eppendorf tubes and centrifuged for 1 minute at $3000 \mathrm{rpm}$ to dry them. Fourth,

176 samplers are washed with $1 \mathrm{~mL}$ of sterile ultrapure water. Finally, DNA is released from the 
177 samplers by immersing them in $1 \mathrm{~mL}$ of $0.1 \mathrm{M}$ phosphate buffer $\mathrm{pH} 8$, vortexed for 30

178 seconds and incubated at room temperature for 1 hour.

179

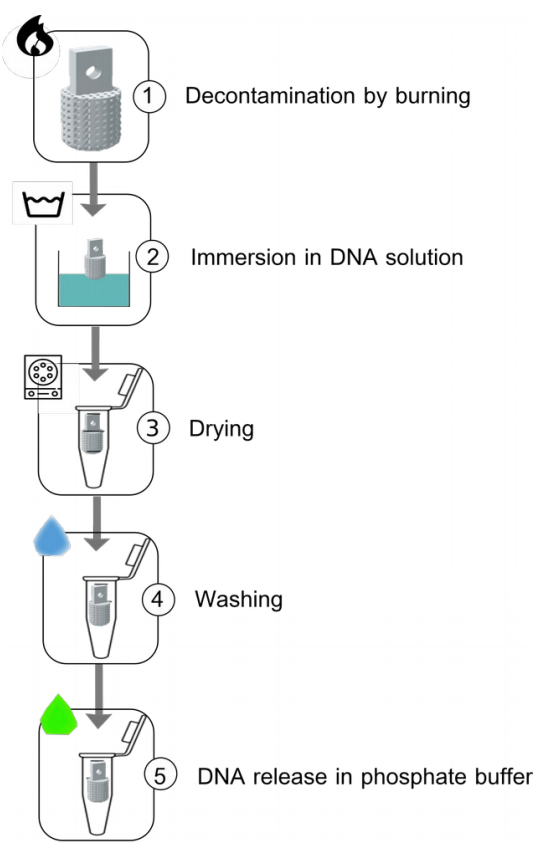

180 FIGURE 2 : DNA binding and release protocol

181

$182 \quad 2.4$ | DNA sampling experiments by HAp samplers

183 2.4.1 | Experiment 1: DNA binding and release

184 A DNA sampling experiment with concentrated DNA fragments of various sizes (i.e. a DNA

185 size marker) was conducted to validate the binding and release protocol and to assess

186 whether DNA fragments of different sizes have different binding efficiencies. After

187 decontamination, one batch of HAp samplers (P1 and P2) was incubated in tubes (1 sampler/

188 tube) containing $2 \mathrm{~mL}$ of a solution of large DNA fragments at $5000 \mathrm{ng} / \mathrm{mL}$ ( $\lambda$ DNA / BstEll

189 Digest, 117-8450 bp). A second batch of HAp samplers was incubated in tubes containing 2

$190 \mathrm{~mL}$ of a solution of short DNA fragments at $2000 \mathrm{ng} / \mathrm{mL}$ (PCR 20 bp Low Ladder, 20-2000

191 bp). Both batches were incubated for 17 hours on a rotary shaker (IKA Roller 6 Digital, 40 
192 rpm). Controls were tubes with $2 \mathrm{~mL}$ of solution and devoided of samplers. Residual DNA in

193 the supernatants was quantified by taking $60 \mu$ aliquots of the supernatant after 45 min and

$19417 \mathrm{~h}$ of incubation. After incubation, HAp samplers were removed from the DNA solutions

195 using sterile clamps and DNA was released according to the protocol in section 2.3. All

196 supernatants aliquots and released DNA solutions were stored at $-20^{\circ} \mathrm{C}$ prior to analysis.

$198 \quad 2.4 .2$ | Experiment 2: repeatability

199 A quantification of repeatability was conducted to test whether HAp samplers can be reused

200 after several cycles of use. A cycle of use is defined here as a thermic treatment phase 201 followed by a DNA binding and release phase. For this purpose, 5 prototypes 1 and 25

202 prototypes 2 HAp samplers were incubated in a concentrated solution of DNA size marker 203 ( DDNA/BstEll Digest $117-8450 \mathrm{pb}$ ) at a concentration of $2.8 \mu \mathrm{g} / \mathrm{mL}$ on a rotary shaker (Roller 20410 Digital IKA) for $17 \mathrm{H}$. This experiment was carried out three times in a row (hereafter called 205 experiments $\mathrm{A}, \mathrm{B}$ and C) under strictly identical conditions, at room temperature $\left(24^{\circ} \mathrm{C} \pm 2^{\circ} \mathrm{C}\right)$ 206 with decontamination through thermic treatment between each use. After incubation, HAp 207 samplers were removed from the DNA solution with sterile clamp, washed and DNA was 208 released with $1 \mathrm{~mL}$ of $0.1 \mathrm{M}$ phosphate buffer $\mathrm{pH} 8$ according to the protocol section 2.3 DNA 209 samples were stored at $-20^{\circ} \mathrm{C}$ prior to analysis.

211 2.4.3 | Experiment 3: microcosm experiment

212 Asellus aquaticus, a small freshwater isopod, was used as a target organism to test the 213 capacity of the HAp samplers to collect eDNA. 40 organisms of A.aquaticus sampled from a 214 natural pond (Lyon, France) in april 2019 were divided into 8 glass microcosms (5 individuals / 215 microcosm) containing $500 \mathrm{~mL}$ of synthetic water (Peltier and Weber, 1985). Positive controls 
216 correspond to microcosms where we injected genomic DNA (final microcosm at $1 \mathrm{ng} / \mathrm{mL}$ )

217 extracted from a pool of 10 A.aquaticus. Negative controls were of two types: control 218 microcosms containing water without DNA and a sampler, and control samplers from which

219 the DNA was released just after the decontamination step (i.e. without incubation in DNA 220 solution). After 24 hours of $A$. aquaticus acclimatization, the two prototypes of HAp samplers 221 were incubated in microcosms (1 sampler / microcosm) for 24 hours. All microcosms were 222 placed in a cold room at $18^{\circ} \mathrm{C}$, spaced $0.5 \mathrm{~m}$ apart and covered to limit the risk of 223 contamination. The organisms were not fed during the experiment to reduce the amount of 224 allochthonous DNA. After incubation, the HAp samplers were collected with sterile clamps 225 and the DNA was released according to section 2.3 of the protocol. Released DNA was 226 purified (Macherey-Nagel TM NucleoSpin TM gel and PCR cleaning kit) to avoid potential 227 inhibition of the downstream qPCR by the phosphate buffer (see next section), following the 228 manufacturer's recommendations. Purified eDNA was stored at $-20^{\circ} \mathrm{C}$ prior to analysis. 


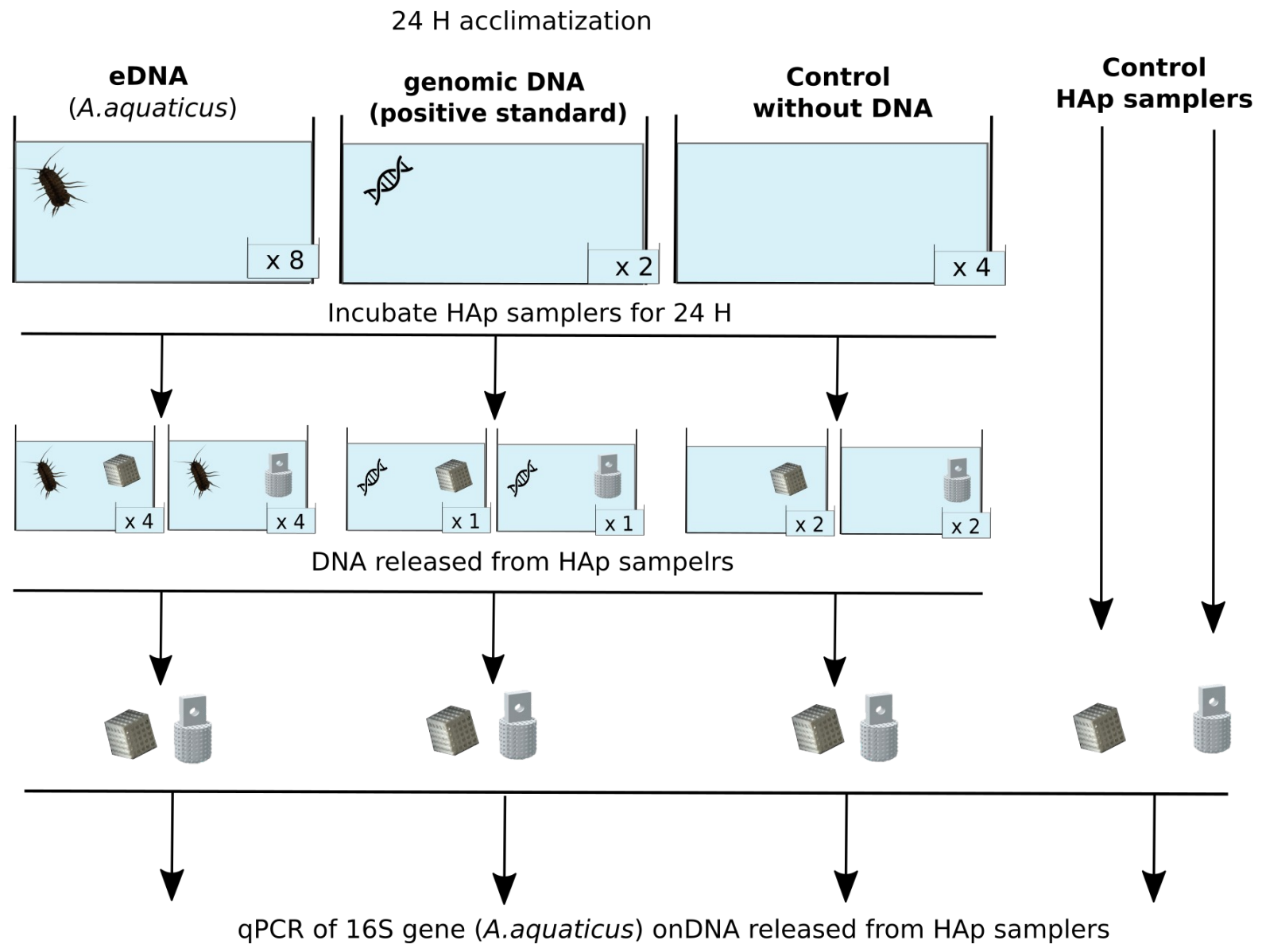

231 FIGURE 3 : Experimental design testing HAp samplers efficacy to recover eDNA from Asellus

232 aquaticus in microcosms.

233

2342.5 | DNA quantification and analysis

235 2.5.1 | Quantification of DNA size marker

236 In the first experiment, DNA binding and release by HAp samplers were evaluated by 237 following the DNA concentration and fragment sizes in three compartments: (1) in the 238 supernatant (i.e. residual DNA), (2) in the washing solution, and (3) in the releasing solution 239 (Fig. 4). DNA was quantified using a QuBit ${ }^{\circledR} 3.0$ fluorometer (Invitrogen) with the dsDNA BR 240 kit (broad range, 2 to $1000 \mathrm{ng} / \mu \mathrm{L}$ ) according to the manufacturer's protocol. The binding of 
241 large DNA fragments (117-8450 pb) was evaluated using gel electrophoresis (1.3\% agarose),

242 and the binding of small fragments (35-2000 bp) using a 2100 Bioanalyzer with an Agilent

243 high-sensitivity DNA chip (Agilent Technologies).

244

245 For the second experiment (repeatability), the amount of DNA released from the HAp

246 samplers was measured by fluorescence (excitation at $480 \mathrm{~nm}$ and emission at $520 \mathrm{~nm}$ )

247 using an Infinite M200 Pro microplate fluorometer (TECAN, Switzerland). A QuantiFluor ${ }^{\circledR}$

248 dsDNA kit was used according to the manufacturer's protocol, with a DNA sample volume of

$24910 \mu \mathrm{L}$ and $190 \mu \mathrm{L}$ of working solution. A five-fold dilution series $(1500-0 \mathrm{ng} / \mu \mathrm{L})$ of standard

250 DNA (Lambda DNA Standard, 100 $\mathrm{g} / \mathrm{mL}$ ) was used to build the standard curve and calculate

251 the sample DNA concentration in $\mu \mathrm{g} / \mu \mathrm{L}$. The results are reported in percentage of recovered

252 DNA (i.e. DNA bound and released).

253 DNAr is the measured concentration of released DNA $(\mu \mathrm{g} / \mathrm{mL})$ per HAp sampler and DNAtot

254 is the initial DNA concentration added in each tube (DNAtot $=2.8 \mu \mathrm{g} / \mathrm{mL}$ ).

255

2562.5 .2 | Quantitative PCR assay for eDNA from A.aquaticus

257 For the third experiment (microcosm experiment), quantitative PCR (qPCR) was used to

258 quantify the amount of A.aquaticus eDNA recovered by the samplers. We designed a pair of 259 primers to specifically amplify a $110 \mathrm{bp}$ fragment of the mitochondrial $16 \mathrm{~S}$ gene of $A$.

260 aquaticus (5’ GGTTTAAATGGCTGCAGTATCC 3’, 5‘ CTTGTGTAATAAAAAGCCTACCTC 3’).

261 The amplification specificity of the primers was tested in silico using primer-BLAST (NCBI)

262 and assessed experimentally through PCR and electrophoresis gel analysis. The qPCR

263 reaction volume was $20 \mu \mathrm{L}$ consisting of $1 X$ SsoAdvanced Universal SYBR Green Supermix

264 (Bio-Rad Laboratories Inc., Hercules, CA), $0.5 \mu \mathrm{M}$ of primers and $2 \mu \mathrm{L}$ of DNA released from 
samplers. All qPCRs assays were run in duplicate in 96 wells plate on a CFX96 Touch $^{\text {TM }}$ Real- $^{-}$

266 Time PCR Detection System (Bio-Rad Laboratories, Inc., Hercules, CA). qPCR cycle started

267 with an incubation at $95{ }^{\circ} \mathrm{C}$ for 10 min followed by 45 cycles of denaturation at $95{ }^{\circ} \mathrm{C}$ for 10

$268 \mathrm{sec}$ and an annealing/extension step at $60^{\circ} \mathrm{C}$ for $20 \mathrm{sec}$ before a final melt curve from 65-95

$269{ }^{\circ} \mathrm{C}\left(0.5^{\circ} \mathrm{C}\right.$ increments). Each qPCR plate included a five-fold dilution series of the genomic

270 DNA at a concentration between 0 and $2.5 \mathrm{ng} / \mu \mathrm{L}$ quantified by a QuBit 3.0 assay.

2772.6 | Statistical analysis

278 Linear mixed-effect models (LMMs) were used to test the influence of the prototype version

279 and of the experiment timing (experiment 2). These models were fitted with the restricted 280 maximum likelihood method using the package nlme. We tested significance of experiment 281 timing and prototype version using likelihood ratio tests (LRT) between the models with and 282 without the tested variable. All analyses were conducted using R (v 4.0.3).

283

2843 | Results

2853.1 | Experiment 1: DNA binding and release

286 We tested the hypothesis that 3D-printed HAp samplers can bind DNA of different fragment 287 sizes by exposing them to two solutions of DNA size markers containing either long (117 to $2888450 \mathrm{bp}$ ) or short DNA fragments (35 bp to $2000 \mathrm{bp}$ ). In the solution containing long DNA 
289 fragments, quantification of DNA concentration (Fig. 4, bottom panel) shows a clear reduction

290 in DNA concentration in the supernatant after 17 hours of exposure to the HAp samplers for

291 both sampler replicates. Once immersed in the releasing solution, and after only 1 minute, the

292 HAp samplers started to release DNA. The amount of released DNA then tripled after 1 hour

293 of incubation. By examining the DNA band profiles in the supernatants and in the releasing

294 solution, we found that P1 bound all DNA fragment sizes from 2000 to $8450 \mathrm{bp}$. Fragments

295 below 2000 bp were not visible on the electrophoresis gel (Fig. 4, top panel). The same

296 observations were made on P2 (see supporting information). 


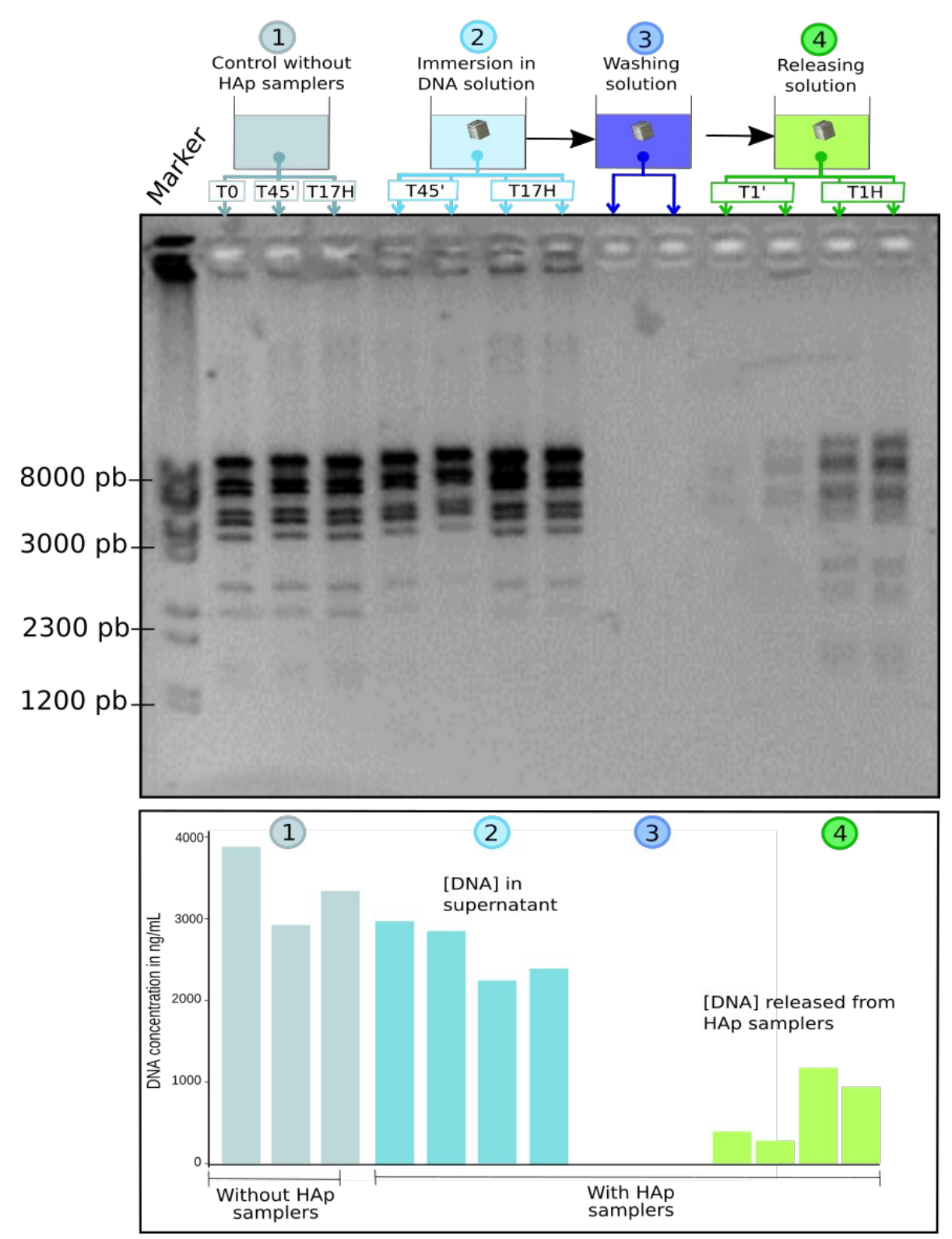

298 FIGURE 4 : DNA binding and release by two replicates of the HAp samplers prototype 1. DNA

299 fragment size (agarose electrophoresis gel, top panel) and concentration (bottom panel) are

300 shown in the following order (left to right): 1) in the control solution without HAp samplers after

3010 minute, 45 minutes and 17 hours, 2) in the DNA solution 45 min and $17 \mathrm{H}$ after addition of

302 HAp samplers, 3) in the washing solution and 4) in the releasing solution 1 min and $1 \mathrm{H}$ after

303 immersion of the HAp samplers. 
305 Repeating the same experiment but using this time short DNA fragments (35-2000 pb) and a

306 microfluidics-based automated electrophoresis system does not show an effect of fragment

307 size on DNA binding (Fig. 5): both samplers prototypes bound and released DNA fragments

308 ranging from 35 to $2000 \mathrm{bp}$ although the resolution of the marker for fragments above $600 \mathrm{bp}$

309 was not optimal.

310

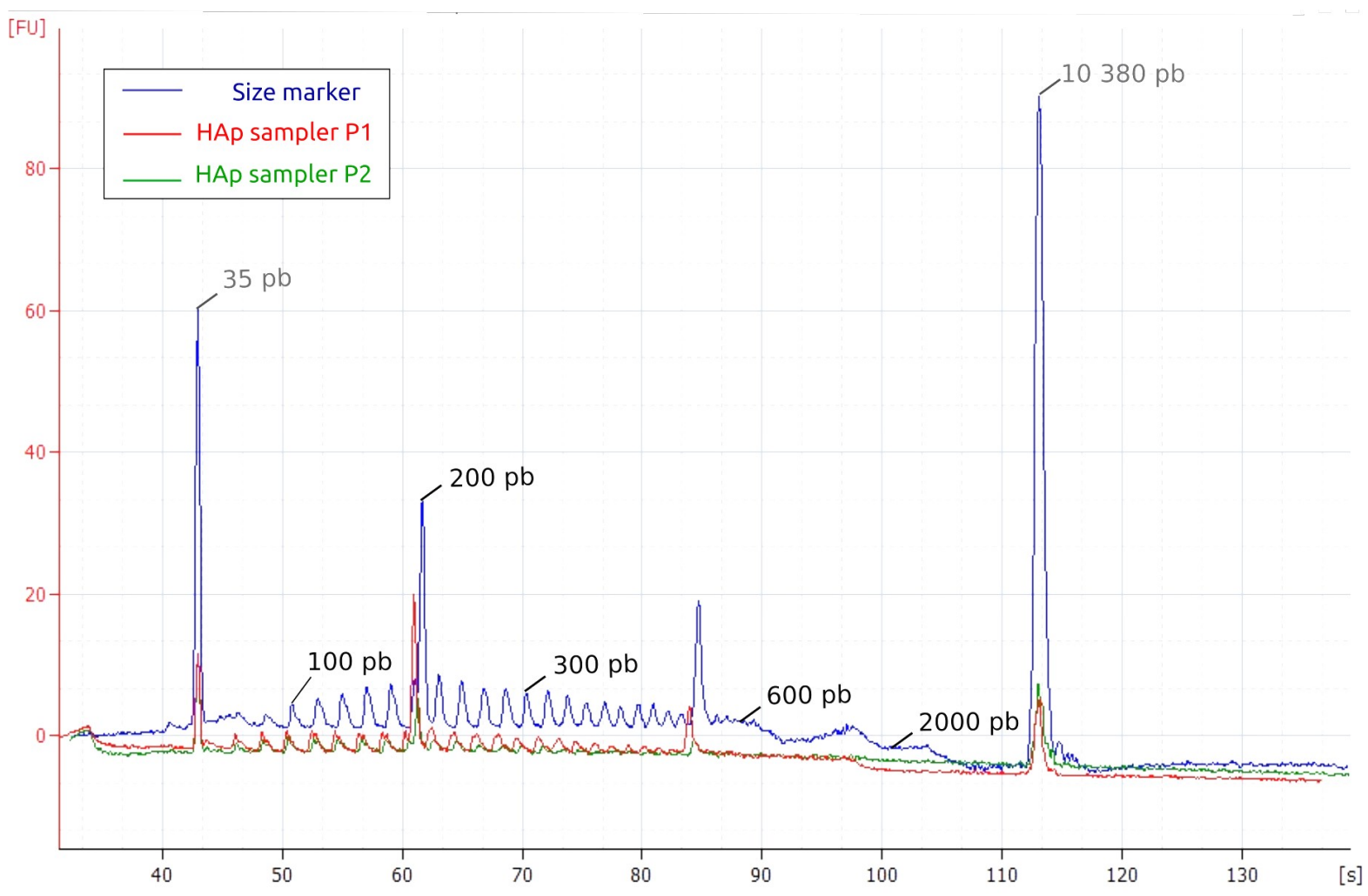

311

312 FIGURE 5 : Electropherograms of the DNA fragments bound and released by the prototype 1

313 (red curve) and prototype 2 (green curve). As a standard, the blue curve represents the profile

314 of the initial DNA marker. The horizontal axis represents the migration time of DNA fragments

315 in seconds, and the vertical axis represents fluorescence. The left-most (35 bp) and right-

316 most (10380 bp) peaks are internal markers. 
3173.2 | Experiment 2: Reusing HAp samplers over time

318 A repeatability experiment was conducted to test the hypothesis that HAp samplers can be 319 reused and that their binding efficacy is stable after several cycles of use. We performed three

320 consecutive cycles of use (experiment A, B and C), each composed of a decontamination,

321 DNA binding and release steps. The percentage of DNA recovered by the samplers was lower

322 in experiment A compared to experiments B and C, with an average of $8 \%, 17 \%$ and $15 \%$,

323 respectively (Fig. 6). In the meantime, experiment A showed a disproportion of samplers (18

324 out of 30, against 0 for experiment B and C) which failed to recover any DNA compared to the

325 other experiments (Fisher exact test, $p<1 \mathrm{E}-10$ ). After removing the samplers which failed to

326 capture any DNA, we tested the influence of the experiment and prototype on the percentage

327 of DNA recovered using a linear mixed-effect models with experiments (A, B and C) and

328 sampler prototypes (P1 or P2) as the fixed effects, and samplers as random effect on the

329 intercept. The experiment and the sampler prototype had no significant effect on the

330 percentage of DNA recovered (LRT, sampler prototype : $\chi_{d f=1}^{2}=4.96, p=0.08$, experiment :

$\left.331 \chi_{d f=2}^{2}=1.16, p=0.28\right)$. Nonetheless, while not associated with any experiment in particular, the

332 percentage of DNA recovered was highly variable. The coefficient of variation of DNA

333 recovered was on average $65 \%$ considering all the samplers and $34 \%$ when excluding the

334 samplers which failed to recover any DNA. Altogether, while we found that the samplers can

335 still recover DNA after several cycles of use, we also discovered that the capacity of HAp

336 samplers to recover DNA is variable and unpredictable: at some times it may not work at all,

337 while at others it may recover a large amount of DNA. 


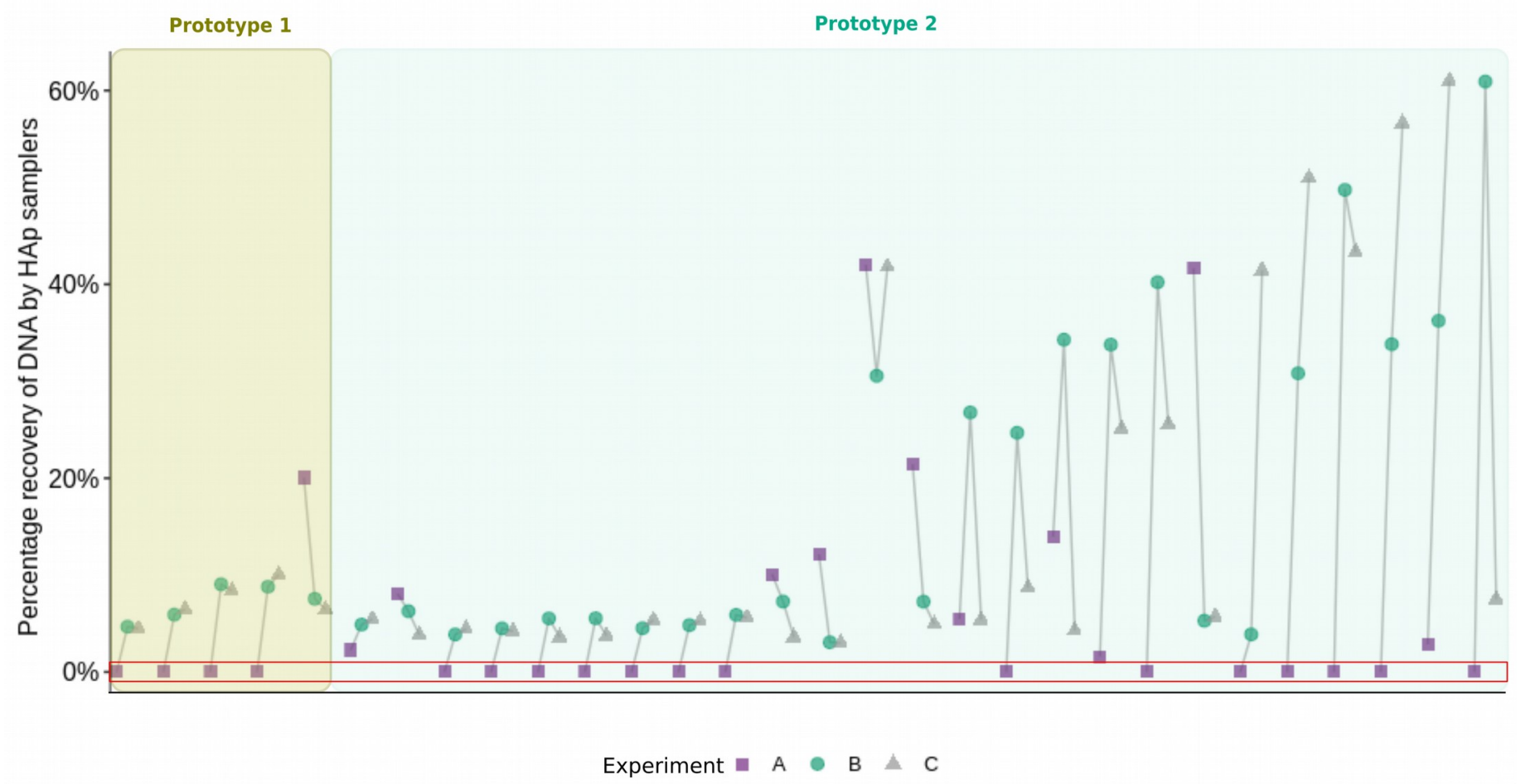

339 FIGURE 6 : Percentage of DNA recovered by two prototypes (P1 and P2) of HAp samplers in

340 three consecutive experiments (A, B and C). 5 P1 and 25 P2 samplers are sorted according

341 to their variance of recovered DNA. Samplers in the red box did not recover any DNA.

3433.3 | Experiment 3: Environmental DNA sampling

344 We deployed the HAp samplers in a microcosm containing isopods (Asellus aquaticus) to test

345 their ability to recover eDNA and used qPCR to quantify the amount of $A$. aquaticus $16 \mathrm{~S}$ gene

346 recovered by the samplers. In a microcosm with no organisms, we observed low levels of

347 DNA that were similar or slightly above the amount of DNA observed in control samplers that

348 were not immersed in a microcosm (Fig. 7). This is indicative of a slight level of cross-

349 contamination between microcosms, and allowed us to determine an amount of 16S DNA

350 below which we cannot differentiate between a contamination and a positive result (limit of 
351 blank, LOB). As expected, using concentrated genomic DNA as a positive control, the

352 samplers recovered large amounts of 16S DNA molecules (Fig. 7). In the microcosm that

353 contained isopods, the amount of 16S DNA molecules was about 3 orders of magnitude

354 lower, with 3 samplers out of 8 below the limit of blank. Overall, the two HAp prototypes

355 recovered $A$. aquaticus eDNA with the same efficiency (Wilcox-test, $p=0.89$ ).

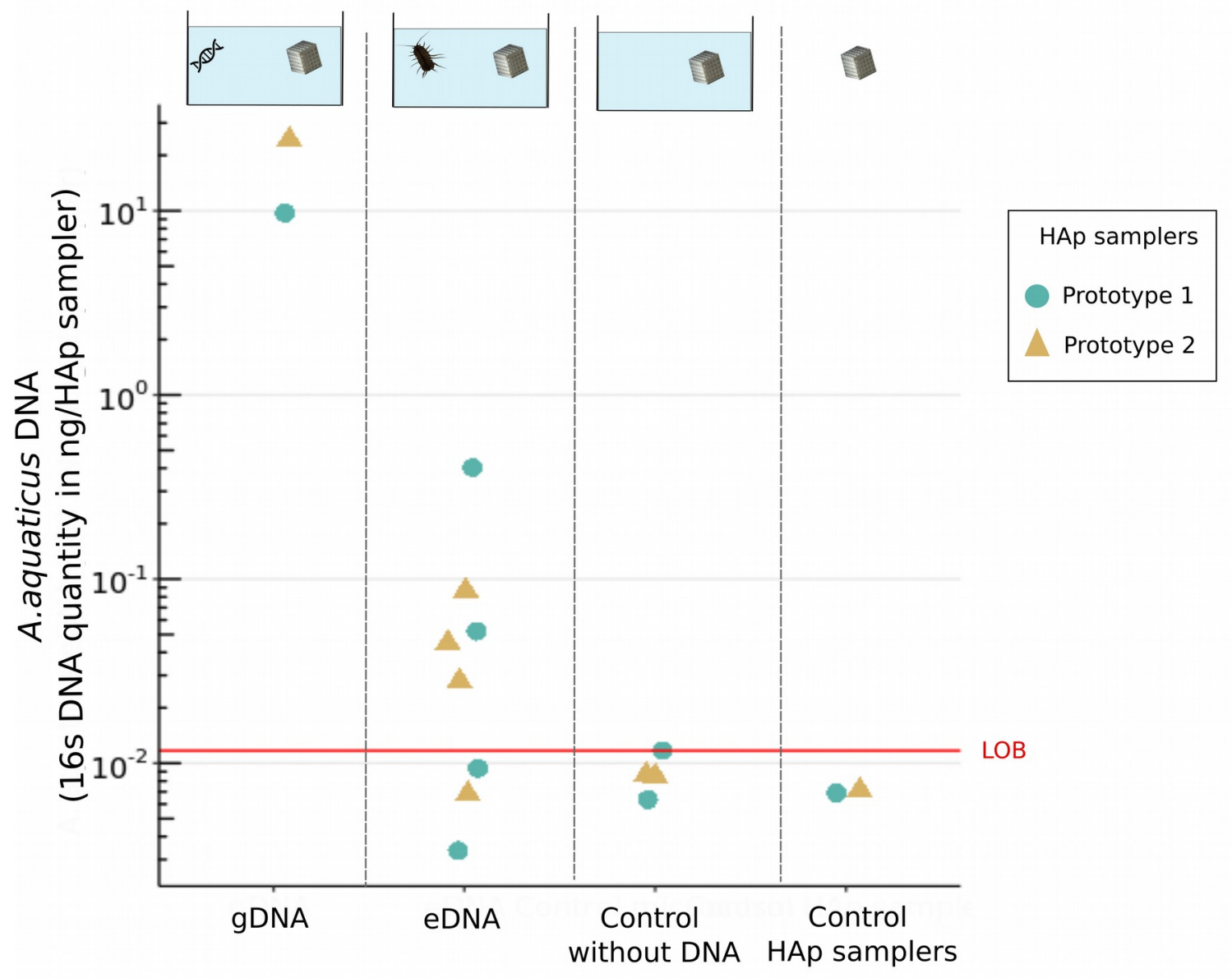

358 FIGURE 7 : Quantity (in log scale) of A.aquaticus $16 S$ gene recovered by the two prototypes

359 of HAp samplers ( $\mathrm{P} 1=$ circle, $\mathrm{P} 2=$ triangle) after $24 \mathrm{~h}$ of incubation in microcosm containing 360 genomic DNA used as a positive control (gDNA) or five individuals of $A$. Aquaticus (eDNA). 
361 Two types of negative controls were used: one control microcosm without DNA (control 362 without DNA), and HAp samplers without microcosm incubation (control HAp samplers). Red

363 line corresponds to the limit of blanks (LOB).

3654 | Discussion

3664.1 | HAp samplers recover artificial DNA and eDNA

367 Our results demonstrated that HAp samplers can passively recover artificial DNA and eDNA. 368 Using artificial DNA, DNA recovery was fast and optimal. In 17 hours, HAp samplers 369 recovered up to 4 times more DNA (i.e. $1.75 \mu \mathrm{g}$ ) than the theoretical quantity we had 370 estimated using a projection of a DNA monolayer on the surface of the samplers (see 371 methods). These results confirm the high binding affinity between DNA and hydroxyapatite 372 reported in literature (Okazaki et al., 2001 ; Del Valle et al., 2014) and suggest that more than 373 one layer of DNA molecules can bind to the HAp surface. To our knowledge, this is the first 374 time that these binding properties are tested and validated on 3D-printed objects. eDNA 375 experiments showed that HAp samplers recovered eDNA from living macro-organisms ( $A$. 376 aquaticus). 5 out of 8 HAp samplers allowed a positive detection of $A$. aquaticus after only 24 377 hours of incubation in microcosm. Given the low densities of these small isopods which, 378 unlike large organisms commonly used in eDNA microcosm experiments (e.g. fish, 379 amphibians; Maruyama et al., 2014; Jo et al., 2020), are likely to release very small amounts 380 of eDNA, and given the short experiment duration, this overall high rate of detection 381 demonstrates the high sensitivity of HAp samplers to detect organisms. 
385

386

387

388

389

390

391

392

393

394

395

396

397

398

399

400

401 Although HAp samplers show a great potential for DNA sampling, repeatability appears to be

402

403

404

405 (Fig. 6), one might have expected that DNA recovery would improve with cycle of use. 406 However, no effect of cycle of use or sampler prototype was found. In some cases, the DNA

407 recovery remained stable over time, in some it increased, and in other it decreased.

408 Surprisingly, while highly variable, there was not a set of samplers or one prototype in

\section{2 | Binding of different DNA fragment size}

While it was hypothesized that DNA fragment size would influence DNA binding (Ogram et al., 1994), we did not find any evidence that certain fragment sizes bind preferentially to the HAp samplers. The samplers recovered DNA fragments of various sizes (i.e. 35-8450 bp), although bands below 2000 bp were not visible on the electrophoresis gel, possibly due to a higher concentration of the larger fragments in the marker solution. However, the sensitive microfluidics-based automated electrophoresis analysis showed that smaller fragments (<2000 bp) were bound and released by HAp samplers. eDNA is a complex mixture of genetic material ranging from cells to more or less degraded free DNA fragments (Wilcox et al., 2015). A sampling method that is not biased toward a given range of fragment sizes is a real advantage for eDNA sampling, in particular in environments where eDNA could be rapidly degraded into small free DNA fragments (Seymour et al., 2018). While free DNA binds to the HAp samplers, it remains to be tested whether other forms of eDNA such as proteo-nucleic complexes or even larger particles can also be collected.

\section{3 | Repeatability issues}

a concerning issue. Many HAp samplers showed extreme variability in DNA recovery among experiments carried out under strictly identical conditions (section 3.2). Given the high number of samplers that did not recover any DNA during the first but not the later experiments

Surprisingly, while highly variable, there was not a set of samplers or one prototype in 
409 particular which was less effective than the others to recover DNA. This unexplained

410 variability highlights the complexity of the binding mechanism between DNA and

411 hydroxyapatite and the factor that controls it, and reinforces the necessity to better

412 understand the evolution of the HAp surface after several DNA cycles of use. According to

413 Okazaki et al. (2001), the binding affinity is based on an electrostatic interaction between the

414 negative charges of the phosphate groups of DNA to the calcium ions at the surface of the

415 hydroxyapatite. This ionic interaction strongly depends on the physico-chemical properties of

416 the sampler surface and the solution in which the binding reaction takes place (Gallo et al.,

417 2018). Among the surface properties, porosity, specific surface area, crystallinity and

418 stoichiometry of the HAp phase (calcium groups can be substituted by other ions) could play

419 a major role in DNA binding. The different manufacturing steps, such as the HAp densification

420 (i.e. sintering), can greatly influence most of these surface properties. In particular, ionic

421 substitution (e.g. carbonatation) and partial dehydration are known to occur frequently in HAp

422 during thermal treatment (Wang, Dorner-Reisel and Müller, 2004; Lafon, 2004) such as the

423 ones used here to decontaminate the samplers before and between experiments, and might

424 be the source of the observed variability. Surface analyse needs to be carried out to identify

425 the physical (e.g. porosity, crystalline phases) and chemical (e.g. surface ionic groups)

426 parameters involved in DNA binding on the HAp surface and the extent to which these

427 parameters are influenced by the manufacturing and use of the sampler (e.g. sintering,

428 debinding, immersion in DNA solution).

429

430

431

432 


\section{5 | CONCLUSION}

434 In view of the democratisation of the use of eDNA, tools are needed to easily and cost-

435 effectively sample eDNA. We demonstrate that 3D passive hydroxyapatite samplers can be

436 designed and used to collect eDNA, albeit some repeatability issues. Provided we can get a

437 better understanding and control of the interaction between eDNA and HAp, this approach

438 offers an alternative sampling solution for eDNA-based biomonitoring. It also opens up an

439 interdisciplinary field at the interface between engineering, surface science and molecular 440 ecology.

\section{ACKNOWLEDGEMENTS}

443 This work was supported by the CNRS Mission pour les Initiatives Transverses et 444 Interdisciplinaires (project XLIFE CAPTAS), the French Biodiversity Agency (OFB), the 445 National Technology Research Association (ANRT) and the company Eurofins Hydrobiologie 446 France. This work was realised thanks to the support of the Graduate School $\mathrm{H}_{2} \mathrm{O}$ 'Lyon (ANR447 17-EURE-0018) and Université de Lyon (UdL) as part of the programme "Investissements 448 d'Avenir" run by Agence Nationale de la Recherche (ANR). We acknowledge Louise Camus 449 for her help with the microcosm experiment, Valentin Vasselon for his advice on experiments 450 with artificial DNA and Jalal Omarakly for the surface analysis of the samplers.

\section{AUTHORS' CONTRIBUTIONS}

452 TL and CM conceived the ideas and designed HAp samplers. Experimental design was 453 conceived by TL, LK and HV. HAp samples were thermal treated and characterized by HR, 454 ST and LG. Laboratory experiments were conducted by HV and LK. Data analysis was 455 conducted by HV and TL. HV and TL led the writing of the manuscript. All authors contributed 456 to the manuscript. 
bioRxiv preprint doi: https://doi.org/10.1101/2021.05.12.443744; this version posted May 14, 2021. The copyright holder for this preprint (which was not certified by peer review) is the author/funder, who has granted bioRxiv a license to display the preprint in perpetuity. It is made available under aCC-BY-NC-ND 4.0 International license.

\section{REFERENCES}

Alvarez, A. J. et al. (1998) 'Amplification of DNA bound on clay minerals', Molecular Ecology, 7(6), pp. 775-778. doi: 10.1046/j.1365-294x.1998.00339.x.

Brundin, M. et al. (2013) 'DNA Binding to Hydroxyapatite: A Potential Mechanism for Preservation of Microbial DNA', Journal of Endodontics, 39(2), pp. 211-216. doi: 10.1016/j.joen.2012.09.013.

Deiner, K. et al. (2017) 'Environmental DNA metabarcoding: Transforming how we survey animal and plant communities', Molecular Ecology, 26(21), pp. 5872-5895. doi: 10.1111/mec.14350.

Del Valle, L. J. et al. (2014) 'DNA adsorbed on hydroxyapatite surfaces', J. Mater.Chem. B, 2(40), pp. 6953-6966. doi: 10.1039/C4TB01184H.

Der Sarkissian, C. et al. (2020) 'Unveiling the Ecological Applications of Ancient DNA From Mollusk Shells', Frontiers in Ecology and Evolution, 8, p. 37. doi: 10.3389/fevo.2020.00037.

Gallo, M. et al. (2018) 'Resorption of calcium phosphate materials: Considerations on the in vitro evaluation', Journal of the European Ceramic Society, 38(3), pp. 899-914. doi: 10.1016/j.jeurceramsoc.2017.07.004.

Gardner, C. M. and Gunsch, C. K. (2017) 'Adsorption capacity of multiple DNA sources to clay minerals and environmental soil matrices less than previously estimated', Chemosphere, 175, pp. 45-51. doi: 10.1016/j.chemosphere.2017.02.030.

Goldberg, C. S. et al. (2016) 'Critical considerations for the application of environmental DNA methods to detect aquatic species', Methods in Ecology and Evolution. Edited by M. Gilbert, 7(11), pp. 1299-1307. doi: 10.1111/2041- 210X.12595.

Hinlo, R. et al. (2017) 'Methods to maximise recovery of environmental DNA from water samples', PLOS ONE. Edited by H. Doi, 12(6), p. e0179251. doi: 10.1371/journal.pone.0179251.

Jo, T. et al. (2020) 'Estimating shedding and decay rates of environmental nuclear DNA with relation to water temperature and biomass', Environmental DNA, 2(2), pp. 140-151. doi: 10.1002/edn3.51.

Kirtane, A., Atkinson, J. D. and Sassoubre, L. (2020) 'Design and Validation of Passive Environmental DNA Samplers Using Granular Activated Carbon and Montmorillonite Clay', Environmental Science \& Technology, 54(19), pp. 11961-11970. doi: 10.1021/acs.est.0c01863.

Lafon, J.-P. (2004) Synthèse, stabilité thermique et frittage d'hydroxyapatites carbonatées (pp. 218).

Langlois, V. S. et al. (2020) 'The need for robust qPCR $\square$ based eDNA detection assays in environmental monitoring and species inventories', Environmental DNA, p. edn3.164. doi: 10.1002/edn3.164.

Levy-Booth, D. J. et al. (2007) 'Cycling of extracellular DNA in the soil environment', Soil Biology and Biochemistry, 39(12), pp. 2977-2991. doi: 10.1016/j.soilbio.2007.06.020.

Mandelkern, M., Elias, J. G., Eden, D., \& Crothers, D. M. (1981). The dimensions of DNA in solution. Journal of molecular biology, 152(1), 153-161. doi: 10.1016/00222836(81)90099-1.

Mariani, S. et al. (2019) 'Sponges as natural environmental DNA samplers', Current Biology, 29(11), pp. R401-R402. doi: 10.1016/j.cub.2019.04.031.

Maruyama, A. et al. (2014) 'The Release Rate of Environmental DNA from Juvenile and Adult 

Fish', PLoS ONE. Edited by M. Stöck, 9(12), p. e114639. Doi: 10.1371/journal.pone.0114639.

Moushomi, R. et al. (2019) 'Environmental DNA size sorting and degradation experiment indicates the state of Daphnia magna mitochondrial and nuclear eDNA is subcellular', Scientific Reports, 9(1), p. 12500. doi: 10.1038/s41598-019-48984-7.

Ogram, A. V. et al. (1994) 'Effects of DNA Polymer Length on Its Adsorption to Soils', Applied and Environmental Microbiology, 60(2), pp. 393-396. doi: 10.1128/AEM.60.2.393-396.1994.

Okazaki, M. et al. (2001) 'Affinity binding phenomena of DNA onto apatite crystals', Biomaterials, vol. 22, no 18, (pp. 2459-2464). doi : 10.1016/S01429612(00)00433-6

Pilliod, D. S. et al. (2013) 'Estimating occupancy and abundance of stream amphibians using environmental DNA from filtered water samples', Canadian Journal of Fisheries and Aquatic Sciences. Edited by J. Richardson, 70(8), pp. 1123-1130. doi: 10.1139/cjfas-2013-0047.

Rahaman, M. N. (2017). Ceramic processing and sintering (Vol. 1). CRC press.

Rivera, S. F. et al. (2021) 'Exploring the capacity of aquatic biofilms to act as environmental DNA samplers: Test on macroinvertebrate communities in rivers', Science of The Total Environment, 763, p. 144208. doi: 10.1016/j.scitotenv.2020.144208.

Seymour, M. et al. (2018) 'Acidity promotes degradation of multi-species environmental DNA in lotic mesocosms', Communications Biology, 1(1), p. 4. doi: 10.1038/s42003-017 0005-3.

Shokralla, S. et al. (2012) 'Next-generation sequencing technologies for environmental DNA research: NEXT-GENERATION SEQUENCING FOR ENVIRONMENTAL DNA' Molecular Ecology, 21(8), pp. 1794-1805. doi: 10.1111/j.1365-294X.2012.05538.x.

Spear, S. F. et al. (2015) 'Using environmental DNA methods to improve detectability in a hellbender (Cryptobranchus alleganiensis) monitoring program', Biological Conservation, 183, pp. 38-45. doi: 10.1016/j.biocon.2014.11.016.

Turner, C. R. et al. (2014) 'Particle size distribution and optimal capture of aqueous macrobial eDNA', Methods in Ecology and Evolution. Edited by M. Gilbert, 5(7), pp. 676-684. doi: 10.1111/2041-210X.12206.

Turner, C. R., Uy, K. L. and Everhart, R. C. (2015) 'Fish environmental DNA is more concentrated in aquatic sediments than surface water', Biological Conservation, 183, pp. 93-102. doi: 10.1016/j.biocon.2014.11.017.

Wang, T., Dorner-Reisel, A. and Müller, E. (2004) 'Thermogravimetric and thermokinetic investigation of the dehydroxylation of a hydroxyapatite powder', Journal of the European Ceramic Society, 24(4), pp. 693-698. doi: 10.1016/S0955-2 219(03)00248-6.

Wilcox, T. M. et al. (2015) 'Environmental DNA particle size distribution from Brook Trout (Salvelinus fontinalis)', Conservation Genetics Resources, 7(3), pp. 639-641. doi: 10.1007/s12686-015-0465-z.

Williams, K. E., Huyvaert, K. P. and Piaggio, A. J. (2017) 'Clearing muddied waters: Capture of environmental DNA from turbid waters', PLOS ONE. Edited by $\mathrm{H}$. Doi, 12(7), p. e0179282. doi: 10.1371/journal.pone.0179282. 